\title{
Vulvovaginal Region
}

National Cancer Institute

\section{Source}

National Cancer Institute. Vulvovaginal Region. NCI Thesaurus. Code C94529.

The body region composed of the vulva and vagina. 